\title{
Evasão escolar no Ensino Médio no Brasil
}

\author{
Wander Augusto Silva ${ }^{1}$
}

\begin{abstract}
Resumo
Este artigo é resultado de pesquisa teórica e empírica sobre a evasão escolar no ensino médio. Indica um histórico de pesquisas realizadas em alguns países sobre a abordagem teórica e metodológica da análise para o fenômeno da evasão escolar no ensino médio, bem como a possibilidade de utilização de estratégias para a permanência de alunos, evitando a evasão escolar. O presente estudo se concentra na esfera das políticas públicas. Apresenta dados estatísticos e análises sobre a evasão escolar nas escolas públicas de ensino médio brasileiras, principalmente entre os anos 20072010, acrescidos de alguns dados mais atualizados. Faz uma análise entre os gastos públicos dos governos estaduais e a taxa de evasão apresentada, por cada estado, no Brasil, nestes anos. Conclui que cerca de $40 \%$ dos alunos que estão nas séries finais do ensino fundamental nem chegam a ingressar no ensino médio; que os estados que mais investem nessa modalidade obtêm uma taxa de abandono menor; e que o fenômeno da evasão escolar no ensino médio no Brasil necessita de um número mais elevado de estudos e pesquisas que indiquem caminhos para a ação de políticas públicas que diminuam esse sério problema educacional e social.
\end{abstract}

Palavras-chave: evasão escolar; ensino médio; Brasil.

1 Professor doutor do curso de Pedagogia e do Programa de Pós-graduação em Educação da Faculdade de Educação da Universidade do Estado de Minas Gerais (PPGE/FaE/UEMG), campus Belo Horizonte. wanderasilva@gmail.com. 


\title{
School Evasion in High School in Brazil
}

\begin{abstract}
This study is the result of a theoretical-empirical research on school dropout on High School. It indicates a historic of researches carried out in some countries on the theoretical-methodological approach of analysis for the phenomenon of school dropout at High School, as well as the possibility for using strategies for maintaining the students, thus avoiding school dropout. The present study concentrates on the sphere of public policies. It presents statistics data and analysis on school dropout of Brazilian public High Schools specially between the years of 2007 e 2010, increased by a few more updated data. It makes a comparison between the public spending of state govern and the dropout rate presented by each Brazilian state in those years. It concludes that around $40 \%$ of the students that are in the final series of Elementary Education does not even get to High School; that the states that invest more in that education modality achieve a lower dropout rate and the school dropout phenomenon at High School level at Brazil needs a greater number of studies and researches that indicate ways for the action of public policies and decrease this serious educational and social problem.
\end{abstract}

Keywords: school dropout; high school; Brazil.

\section{Introdução}

Este artigo $^{2}$ apresenta um pequeno estudo sobre a evasão escolar no ensino médio no Brasil, indicando que o fenômeno da evasão escolar não é de fácil definição, identificação e classificação. Além da dificuldade de determinar o conceito de "evasão", outros obstáculos ainda precisam ser superados, tais como a dificuldade em se obter dados sobre a evasão, em se identificar os períodos que são considerados pelos organismos que coletam informações sobre essa questão, e em se identificar metodologias adotadas nos estudos. Não bastassem essas limitações, também é difícil localizar os jovens que abandonaram a escola e conseguir que eles falem sobre o assunto, devido, muitas vezes, ao desconforto que a situação representa para eles.

O abandono escolar é uma realidade no ensino no Brasil em todos os níveis e modalidades, entretanto, chega a ser alarmante o número de evadidos no ensino médio; entre os anos de 2007-2010, dados estatísticos indicavam uma evasão de aproximadamente $25 \%$ de alunos. Porcentagem de evasão que continuava em semelhante patamar ainda no ano de 2015. Outra evasão de grande proporção é a de

2 Baseado em parte da tese de doutorado do autor, sendo acrescida e atualizada com alguns dados e estudos. 
alunos brasileiros que, ao concluírem o ensino fundamental, abandonam os estudos e nem iniciam o ensino médio. Em 2010, havia cerca de 31 milhões de alunos estudando no ensino fundamental, enquanto os que estudavam no ensino médio representavam somente 8 milhões de jovens. Em números absolutos, apenas 30\% dos jovens que deveriam fazer o ensino médio o fazem.

Este artigo está delimitado ao fenômeno da evasão escolar que ocorre no ensino médio, etapa final da educação básica, que afeta a população jovem brasileira em sua faixa etária de adolescentes de 14 a 17 anos, bem como de jovens com idade entre 18 e 24 anos que, além de estudo, por necessidade econômica, também trabalham. Conforme Abramo (2007), existe um relativo interesse no estudo sobre a juventude que advém da formulação do Estatuto da Criança e do Adolescente (ECA) no Brasil; entretanto, ao longo dessas décadas, a oferta de políticas públicas ao jovem e a sua discussão política foi relativizada e pulverizada. Já Sposito (2010) indica, ao contrário, o surgimento de dimensões decorrentes da ampliação da oferta de ensino público, os novos formatos do mercado de trabalho, a ocupação dos espaços urbanos e novas formas de socialização que se tornam relevantes para pensar as “culturas juvenis”. O presente estudo discute e reflete sobre a falta de políticas públicas destinadas a esses jovens através de dados e conceitos sobre o abandono escolar nessa faixa etária, principalmente se considerando que os jovens no Brasil compreendiam, segundo o IBGE, no ano de $2010^{3}$, a maior proporção da população, e que estão entre o final dos estudos básicos e o início da vida com trabalho.

\section{Estudos sobre a evasão em alguns países}

Comumente, associa-se a imagem de abandono escolar ao aluno que sai da escola e não retorna no prazo ou no período de conclusão regulamentado para receber o diploma. Segundo o estudo feito sobre a evasão nas universidades públicas (BRASIL, 1996), o abandono escolar seria a saída definitiva do aluno do curso de origem, sem a conclusão do mesmo, ou a diferença de tempo entre o ingresso e a conclusão, após uma geração completa. De acordo ainda com essa pesquisa, poderiam ser caracterizadas várias formas de evasão escolar. Um exemplo de evasão de curso é o desligamento do estudante do curso superior, em situações diversas, tais como: abandono (deixa de se matricular); desistência (oficial); transferência ou (re)opção (mudança de curso); trancamento; exclusão por norma institucional.

3 IBGE, Sinopse dos Resultados do Censo 2010, site IBGE. 
Por sua vez, Dore e Lüscher (2008) ressaltam que as pesquisas sobre evasão no ensino médio e, em particular, no ensino médio profissionalizante são praticamente inexistentes no Brasil. As autoras, em diálogo com autores internacionais, questionam o conceito de evasão escolar relacionado a uma educação que não foi completada. Na visão delas, existem alunos que, mesmo realizando o ensino obrigatório, não seguem o curso de forma contínua, indo e voltando à escola em períodos de tempos descontínuos e variáveis.

De acordo com as referidas autoras, para investigar o fenômeno da evasão escolar, devem ser consideradas três dimensões conceituais: o nível de escolaridade, a questão da tipologia quanto à descontinuidade nos estudos e à não conclusão e, por fim, as razões que motivam o abandono escolar. Dore e Lüscher (2008) acrescentam ainda que um elemento fundamental para tal estudo é a definição do recorte da investigação pelo pesquisador, tendo em vista a análise do problema: se seu ponto de partida é o indivíduo, a escola ou o sistema social em que o aluno se insere. Citando o pesquisador norte-americano Rumberger ${ }^{4}$, as autoras identificam duas perspectivas principais para o estudo da evasão: a individual, que se refere ao estudante, às circunstâncias do percurso escolar do estudante, e a institucional, a partir da qual são considerados os valores, os comportamentos e as atitudes para maior ou menor permanência do estudante na escola.

Tendo em vista a escassez de estudos sobre a evasão escolar no ensino médio técnico no Brasil, Dore e Lüscher (2008) sistematizaram estudos já realizados sobre a evasão no ensino superior, em relação ao qual se encontra o volume maior de estudos sobre o abandono escolar. No que diz respeito às causas mais relevantes para o abandono escolar no ensino superior, encontram-se a condição socioeconômica da família, a necessidade de trabalhar, as dificuldades resultantes de formação no ensino fundamental, a repetência e o desempenho escolar insuficiente, a frustração em relação ao curso escolhido e, por fim, os fatores intraescolares, como currículo e carga horária das disciplinas.

Mais recentemente, contudo, o tema vem ganhando a atenção de pesquisadores da educação no Brasil. Até a década de 1970, o foco das pesquisas sobre a evasão, segundo Freitas (2009), concentrava-se nas razões que levam os jovens a abandonarem a escola. A partir do início dos anos de 1980, as pesquisas incorporaram outros aspectos significativos ao estudo do problema, focalizando os motivos que levaram os estudantes a persistirem na escola. Os objetivos de tais pesquisas são prevenir o abandono e identificar formas para encorajar a permanência do aluno na escola.

Fazendo uma retrospectiva histórica dos estudos sobre a evasão escolar no mundo,

4 RUMBERGER, R. In: ORFIED, Gary (Ed.). Dropouts in America: confronting the graduation rate crisis. Cambridge, MA: Harvard Education Press, 2004. p. 131-155. 
a partir da década de 1930, Freitas (2009) os classifica em sete categorias e modelos de pesquisa: I) estudos descritivos (antes da II Guerra Mundial); II) estudos preditivos (entre a II Guerra Mundial e 1950); III) estudos sobre a adequação dos estudantes à instituição de ensino (1950 a 1960); IV) estabelecimento de tipologia dos evadidos e suas experiências na escola (fins de 1960); V) análise de variáveis institucionais (início da década 1970); VI) estudos sobre o modo pelo qual as escolas incentivam os estudantes a completarem o curso (fins de 1970); e VII) estudos sobre a qualidade da interação entre professor e aluno, tipo de diploma ou cerificação ao final do curso e ajuda financeira ou bolsa aos estudantes (início dos anos de 1980). Atualmente, ainda segundo a referida autora, tem aumentado o leque de estudos sobre a evasão e a permanência de estudantes, considerando-se principalmente os efeitos das políticas sociais sobre o estudante e seu entorno sociocultural.

Para visualizar melhor alguns estudos realizados sobre a permanência e a evasão escolar, será apresentado, a seguir, um quadro sinóptico elaborado por Freitas (2009), indicando, sinteticamente, o foco de alguns estudos teóricos no período de 1962 a 1993, nos Estados Unidos da América (EUA). 
Evasão Escolar no Ensino Médio no Brasil

Quadro 1 - Alguns estudos realizados sobre evasão e permanência de estudantes no período de 1962 a 1993, nos EUA

\begin{tabular}{|c|c|c|}
\hline Autor, ano, teoria & Foco do estudo & Comentário \\
\hline $\begin{array}{l}\text { Astin }(1977,1983), \text { EUA - } \\
\text { Teoria do envolvimento. }\end{array}$ & $\begin{array}{l}\text { Quanto mais envolvido com a } \\
\text { instituição, maior probabilidade } \\
\text { de permanência. }\end{array}$ & $\begin{array}{l}\text { A satisfação é uma forte } \\
\text { variável com efeito positivo na } \\
\text { permanência. }\end{array}$ \\
\hline $\begin{array}{l}\text { Bean }(1980,1983), \text { EUA - } \\
\text { Teoria organizacional sobre } \\
\text { falta e evasão de trabalhadores } \\
\text { aplicada à educação. }\end{array}$ & $\begin{array}{l}\text { Usa conceitos de estudos } \\
\text { organizacionais sobre a falta } \\
\text { de trabalhadores ao emprego } \\
\text { e sua evasão. Examina como } \\
\text { os atributos das organizações } \\
\text { organizacionais e a estrutura de } \\
\text { recompensa afetam a satisfação } \\
\text { e a persistência dos estudantes. }\end{array}$ & $\begin{array}{l}\text { Estabelece uma forte relação } \\
\text { entre satisfação e persistência } \\
\text { de estudantes e trabalhadores. }\end{array}$ \\
\hline $\begin{array}{l}\text { Bean e Metzner (1985), EUA } \\
\text { - Evasão de estudantes não } \\
\text { tradicionais. }\end{array}$ & $\begin{array}{l}\text { Fatores ambientais têm mais } \\
\text { impacto do aluno adulto de } \\
\text { deixar de estudar do que as } \\
\text { variáveis acadêmicas. }\end{array}$ & $\begin{array}{l}\text { Estudantes não tradicionais } \\
\text { podem estar em uma faixa } \\
\text { etária acima da regularmente } \\
\text { considerada adequada ao nível } \\
\text { estudado. }\end{array}$ \\
\hline $\begin{array}{l}\text { Price (1977) - Evasão dos } \\
\text { trabalhadores na indústria. }\end{array}$ & $\begin{array}{l}\text { Seis variáveis sobre o controle } \\
\text { da organização: integração } \\
\text { social no emprego, pagamento, } \\
\text { participação na tomada de } \\
\text { decisões, rotina de trabalho, } \\
\text { conhecimento do que deve fazer } \\
\text { no trabalho e tratamento justo. }\end{array}$ & $\begin{array}{l}\text { Adaptado e muito usado em } \\
\text { educação. }\end{array}$ \\
\hline $\begin{array}{l}\text { Kamens (1971, 1974), EUA - } \\
\text { Tamanho da instituição. }\end{array}$ & $\begin{array}{l}\text { Dados multi-institucionais para } \\
\text { demonstrar como instituições } \\
\text { de ensino superior de grande } \\
\text { porte e complexidade têm, } \\
\text { comparativamente, a menor } \\
\text { taxa de evasão. }\end{array}$ & \\
\hline $\begin{array}{l}\text { McNeely (1973), EUA - } \\
\text { Desistência do estudante do } \\
\text { ensino superior. }\end{array}$ & $\begin{array}{l}\text { Múltiplos fatores, inclusive o } \\
\text { tempo do curso até a graduação, } \\
\text { quando ocorre a evasão e impacto } \\
\text { do tamanho da evasão. }\end{array}$ & \\
\hline Spady (1970), EUA - Interação. & $\begin{array}{l}\text { Interação entre as características } \\
\text { do estudante e ambiente } \\
\text { institucional. }\end{array}$ & \\
\hline $\begin{array}{l}\text { Summerskill (1962) - Atributos } \\
\text { pessoais }\end{array}$ & $\begin{array}{l}\text { Relação entre atributos pessoais } \\
\text { e motivo para evadir. }\end{array}$ & \\
\hline $\begin{array}{l}\text { Tinto (1975, 1993), EUA - } \\
\text { Integração social e acadêmica. }\end{array}$ & $\begin{array}{l}\text { Integração social e acadêmica } \\
\text { formal e informal, com ambos } \\
\text { os sistemas (acadêmico e social). }\end{array}$ & $\begin{array}{l}\text { Modelo largamente usando } \\
\text { nas pesquisas sobre educação } \\
\text { presencial e a distância. }\end{array}$ \\
\hline
\end{tabular}

Fonte: Freitas, 2009. 
O quadro 1 indica, em síntese, uma possibilidade de estudo sobre o fenômeno do abandono escolar dentro de algumas perspectivas, entre elas, a de que, quanto maiores e melhores o envolvimento e a participação do aluno e do aluno/trabalhador com sua escola, sua formação e seu estudo, menor será a evasão. Outro aspecto seria a atenção especial a ser oferecida a estudantes mais velhos, considerados fora da faixa etária para cursar o ensino médio.

No Chile, conforme Martínez (2014), o atual quadro das políticas públicas destinadas à juventude necessita de um redesenho integral e transversal que elimine um tipo de formação oligárquica dominante, destinada às classes mais favorecidas, e uma educação de segundo plano, destinada às classes trabalhadoras. Essa educação, na instrução, de segundo plano é responsável não somente pelo elevado índice de abandono escolar dos jovens chilenos, mas também pela má formação humana e cidadã. Martínez (2014) indica que, no Chile, como em toda a América Latina, existe uma “cuestón juvenil” a se enfrentar, produto de diversos projetos de desenvolvimento que têm afetado a vida e a trajetória escolar dos jovens dessa região, vindos de uma aguda pobreza, da má qualidade de serviços sociais, de saúde, de permanência nos estudos e da difícil inserção no mercado de trabalho formal. A situação no ensino médio no Chile, apesar de algumas melhorias nos últimos anos, é preocupante, pois, no geral, existe uma taxa de evasão escolar em torno de $20 \%$; em jovens em situação de pobreza, aumenta para $70 \%$.

Um bom estudo sobre a evasão escolar na América Latina, em particular, na comparação sobre esse fenômeno entre o Brasil e a Argentina, é o realizado por Passades (2014), focado principalmente na condição de trabalhador de adolescentes entre 15 e 17 anos e jovens entre 18 e 24 anos. Um dos primeiros comparativos feitos pela autora é a obrigatoriedade do ensino médio, o que, no Brasil, foi instituído em $2009^{5}$, e, na Argentina, já existe desde $2006^{6}$ (com a indicação de prescrição de mecanismos para a prevenção da evasão), ou seja, a Argentina demonstra uma preocupação com o ensino médio de maior relevo do que o Brasil. Indica também essa autora que, nas áreas urbanas da Argentina, para o período compreendido entre 2001 e 2011, mais de $40 \%$ dos adolescentes e jovens entre 15 e 24 anos dedicam-se apenas aos estudos e não trabalham, enquanto que, no Brasil, a porcentagem máxima alcançada, para o mesmo período, de jovens que se dedicam apenas aos estudos é de 27,52 \%; esse vetor de análise mostra que a tendência de evasão no ensino médio seria maior no Brasil. As taxas de matrículas em 20117 , de alunos que findaram o ensino fundamental e que iniciaram o ensino médio, são maiores, se comparadas com as mesmas taxas dos alunos brasileiros; dessa forma, a evasão nos anos iniciais do ensino médio na Argentina demonstra ser menor que no Brasil.

5 Através da Emenda Constitucional n. 59, de 2009, abrangendo 14 anos de duração, indo dos 4 aos 17 anos de idade.

6 Pela Ley de Educación Nacional, n. 26.206

7 Conforme dados da UNESCO (Brasil, fonte: IBGE; Argentina, fontes: EPH e INDE). 
Documento da Organização das Nações Unidas para a educação, a ciência e a cultura (UNESCO) e do Fundo das Nações Unidas para a Infância (UNICEF), publicado em $2012^{8}$, revelava que, em 2008, na América Latina e no Caribe, dos 117 milhões de crianças e adolescentes em idade para cursar o ensino fundamental ou médio, 6,5 milhões estavam fora da escola. Além disso, 15,6 milhões de crianças e adolescentes tinham dois ou mais anos de atraso, com risco de abandonarem a escola.

Um dos fatores que mais contribuem e afetam a evasão na América Latina, conforme a UNICEF (2015), é a desigualdade de distribuição de renda existente nesses países, o que afeta toda a estrutura educacional, gerando novas desigualdades sociais que se refazem em desigualdades culturais e educacionais. Esse modelo hegemônico de ensino na América Latina, além de buscar uma massificação do conhecimento, não oferece condições para a difusão do conhecimento de forma igualitária entre os estudantes, excluindo-os por classe social, gênero, localização geográfica e etnia. Nesse mesmo documento, a UNICEF (2015) mostra que chega a 25 milhões a quantidade de pessoas entre 20 e 24 anos que não concluíram o ensino médio na região. Embora um pequeno número de países ainda mantenha as diferenças a favor da população masculina, a caracterização dessa população mostra que o cenário regional se caracteriza pela paridade de gêneros na deserção escolar. Contribuem para o abandono escolar outras variáveis, como as condições das populações rurais, de indígena e de pessoas afrodescendentes. Apesar dessas diferenças, o elemento central que explica o fenômeno da deserção na América Latina e no Caribe refere-se aos níveis de renda e à condição de pobreza das residências.

\section{Alguns estudos sobre evasão no Brasil}

O problema da evasão escolar analisado neste artigo refere-se principalmente à escola pública e gratuita; embora também ocorra um grande número de abandono de alunos em escolas privadas. Os principais motivos para a evasão em escolas particulares, de acordo com Martins (2007), são a mensalidade elevada, a dificuldade financeira momentânea e a falta de financiamento do curso. Entretanto, existem metodologias, para se identificar o tipo de evasão e para se localizar onde ela ocorre com maior frequência, que podem ser empregadas tanto em estudos relativos a escolas públicas quanto a privadas. Algumas ações relevantes para a sistematização do fenômeno da evasão escolar e seus possíveis tipos em qualquer modalidade escolar são enumeradas por Biazus (2004), consistindo em: identificar o período em que a evasão ocorre com maior intensidade; identificar o ano e a série em que ocorrem índices mais elevados de abandono; fazer uma relação quantitativa entre o número de alunos evadidos, em comparação com o número de matriculados; identificar as principais causas para o

8 UNESCO/UNICEF. Todas as crianças na escola em 2015; Iniciativa global pelas crianças fora da escola, 2012. 
abandono; identificar o estado civil, a faixa etária, o sexo e o rendimento familiar do aluno e os cursos em que existe maior número de evadidos.

Como outros autores, também Biazus (2004) assinala que, no Brasil, a literatura que trata do tema da evasão escolar concentra-se nos níveis de graduação e de pósgraduação. Entre os anos de 1992 e 1994, afirma o referido autor, o Ministério da Educação (MEC) propôs e intensificou estudos sobre evasão, com a criação do Programa de Avaliação das Universidades Brasileiras (PAIUB). Este Programa não conseguiu apresentar, com plenitude, os motivos da evasão no ensino da graduação, porém, foi elaborado um relatório técnico (BRASIL, 1996) indicando fatores que propiciam a evasão, bem como suas características.

Na verdade, vários fatores causadores de evasão indicados pelo PAIUB, senão todos, podem ser identificados também no ensino médio, tais como: o nível cultural da família; a necessidade de busca de trabalho para sustento próprio e da família; o conhecimento e o interesse do aluno pelo curso; a falta de conhecimento e de estratégias pedagógicas da escola para evitar o abandono escolar; a falta de professores capacitados; a infraestrutura física da escola inadequada à demanda de alunos; a falta de base educacional. Esses fatores podem ser vistos no quadro a seguir. 
Quadro 2 - Fatores que propiciam a evasão escolar, conforme estudo do MEC (PAIUB) - cursos de graduação no Brasil - (1996) e de Biazus (2004)

\begin{tabular}{|c|c|c|}
\hline $\begin{array}{l}\text { Fatores referentes a } \\
\text { características individuais } \\
\text { do estudante }\end{array}$ & $\begin{array}{l}\text { Fatores internos às } \\
\text { instituições }\end{array}$ & $\begin{array}{l}\text { Fatores externos às } \\
\text { instituições }\end{array}$ \\
\hline $\begin{array}{l}\text { a) Relativos à habilidade } \\
\text { de estudo; relacionados à } \\
\text { personalidade; decorrentes da } \\
\text { formação escolar anterior. } \\
\text { b) Vinculados à escolha precoce } \\
\text { da profissão; relacionados } \\
\text { a dificuldades pessoais de } \\
\text { adaptação à vida universitária. } \\
\text { c) Decorrentes da } \\
\text { incompatibilidade entre a vida } \\
\text { acadêmica e as exigências do } \\
\text { mundo do trabalho. } \\
\text { d) Decorrentes do desencanto } \\
\text { ou da desmotivação dos alunos } \\
\text { com cursos escolhidos em } \\
\text { segunda ou terceira opção. } \\
\text { e) Decorrentes de dificuldades } \\
\text { na relação ensino- } \\
\text { aprendizagem, traduzidas em } \\
\text { reprovações constantes ou na } \\
\text { baixa frequência às aulas. } \\
\text { f) Decorrentes da } \\
\text { desinformação a respeito } \\
\text { da natureza dos cursos; } \\
\text { decorrente da descoberta de } \\
\text { novos interesses que levam à } \\
\text { realização de novo vestibular. }\end{array}$ & $\begin{array}{l}\text { a) Peculiares a questões } \\
\text { acadêmicas: } \\
\text { • currículos desatualizados, } \\
\text { alongados; } \\
\text { • rígida cadeia de pré-requisitos, } \\
\text { além da falta de clareza sobre } \\
\text { o próprio projeto pedagógico } \\
\text { do curso. } \\
\text { b) Relacionados a questões } \\
\text { didático-pedagógicas, por } \\
\text { exemplo: } \\
\text { • critérios impróprios de } \\
\text { avaliação do desempenho } \\
\text { discente; } \\
\text { • a falta de formação } \\
\text { pedagógica ou o desinteresse do } \\
\text { docente; } \\
\text { • a falta de formação } \\
\text { pedagógica ou o desinteresse do } \\
\text { docente; } \\
\text { • a ausência ou o pequeno } \\
\text { número de programas } \\
\text { institucionais para o estudante. } \\
\text { c) Decorrentes da cultura } \\
\text { institucional de desvalorização } \\
\text { da docência na graduação: } \\
\text { • insuficiente estrutura de } \\
\text { apoio ao ensino de graduação } \\
\text { (laboratórios de ensino, } \\
\text { equipamentos de informática } \\
\text { etc.); } \\
\text { • inexistência de um sistema } \\
\text { público nacional que viabilize } \\
\text { a racionalização da utilização } \\
\text { das vagas, afastando a } \\
\text { possibilidade da matrícula em } \\
\text { duas universidades. }\end{array}$ & $\begin{array}{l}\text { a) Relativos ao mercado de } \\
\text { trabalho. } \\
\text { b) Relacionados ao } \\
\text { reconhecimento social da } \\
\text { carreira escolhida. } \\
\text { c) Afetos à qualidade do } \\
\text { ensino fundamental e médio, } \\
\text { vinculados a conjunturas } \\
\text { econômicas específicas. } \\
\text { d) Relacionados à } \\
\text { desvalorização da profissão, } \\
\text { por exemplo, o caso das } \\
\text { licenciaturas; vinculados a } \\
\text { dificuldades financeiras do } \\
\text { estudante. } \\
\text { e) Relacionados às dificuldades } \\
\text { de se atualizar a universidade } \\
\text { ante os avanços tecnológicos, } \\
\text { econômicos e sociais da } \\
\text { contemporaneidade. } \\
\text { f) Relacionados à ausência } \\
\text { de políticas governamentais } \\
\text { consistentes e continuadas, } \\
\text { voltadas para o ensino de } \\
\text { graduação. }\end{array}$ \\
\hline
\end{tabular}

Fonte: Adaptado de Brasil (1996) e Biazus (2004). 
No que diz respeito à permanência do aluno na escola, Biazus (2004) destaca alguns fatores: o apoio e a valorização familiar ao estudo; o apoio de amigos ou de grupos sociais que valorizam a educação; informações sobre programas de incentivo ao estudo que proporcionem oportunidades de desenvolvimento; corpo docente que motive e que encoraje o aluno; informações sobre os benefícios de uma educação sólida para a vida e a profissão; exemplo de casos de sucessos de ex-alunos para motivar o aluno em risco. O conhecimento desses fatores (BRASIL, 1996) também possibilitou formular com mais precisão os instrumentos de análise desta investigação.

O estudo de Silva (2013) sobre abandono e permanência escolar, em específico no ensino médio e no ensino médio profissionalizante no Brasil, fornece bons elementos para a busca e o entendimento sobre os motivos para a evasão. Esse autor indica que inexiste um sistema governamental oficial de rastreamento de evadidos no Brasil, assim como não existem métodos e coletas de dados sistematizados e padronizados no estudo do abandono escolar, com o agravante da coleta de informações sobre a evasão escolar também ser complexa e rara, devido à grande dificuldade de identificação, localização e aceitação do evadido como investigado.

Silva (2013) faz um resumo e uma síntese geral sobre os principais motivos que podem levar à evasão escolar em qualquer modalidade de ensino. O maior deles seria a pobreza das famílias e dos estudantes. O nível cultural da família é elemento forte para que o aluno abandone ou não os estudos; também a necessidade de busca por trabalho e a consequente dificuldade de conciliar trabalho e estudo é um fator de peso; assim como o desconhecimento do aluno sobre o curso que faz, levando à não adequação e à insatisfação; ainda, a falta de formação de professores para lidarem com os alunos em situação de abandono e, por fim, a falta de base educacional e de conteúdo do aluno, que gera repetência e desinteresse.

A pesquisa sobre evasão escolar de Silva (2013) é baseada na coleta de dados primários e em informações de mais de 2.500 alunos do ensino médio que participavam de um programa de ensino profissionalizante de ensino médio no estado de Minas Gerais, entre os anos de 2007 e $2010^{9}$. Tal programa oferecia, de forma gratuita, um curso profissionalizante técnico de nível médio; mesmo não tendo custos de mensalidade, ocorria alta taxa de abandono, entre $20 \%$ e $28 \%$, em média geral, entre os que participavam do programa. Os dados da pesquisa mostravam, em uma interpretação geral sobre os motivos para o abandono, conforme relatavam os alunos evadidos, que: a) o maior volume de evasão de alunos no programa se dava no primeiro mês; 48,4\% abandonavam antes de começar ou até a terceira semana do início do curso; b) 80\% dos evadidos eram alunos que já tinham concluído o ensino médio; c) os alunos do período da manhã, 36,48\% dos evadidos, tinham maior propensão a abandonarem o curso; d) existia dificuldade em conciliar trabalho e estudo (55\%); e) também existia dificuldade financeira para permanecer no curso (31\%); f) outro

9 Programa de Ensino Profissionalizante (PEP/MG). 
fator era a inadequação do aluno ao turno (29\%); g) o tempo e o dinheiro gastos com transporte (15\%) também geravam dificuldade para a permanência no curso; e h) o motivo de a escola estar longe de casa (11\%).

Na mesma pesquisa, Silva (2013) indica os motivos que poderiam evitar o abandono escolar e gerar uma permanência do aluno; as respostas dadas pelos alunos mostravam que o principal elemento seria um auxílio financeiro para custear o curso. Também como elementos secundários os alunos elencaram a vontade de mudar de curso e uma maior atenção da escola com suas necessidades educacionais.

\section{Estratégias de prevenção contra a evasão escolar}

Vicent Tinto, autor norte-americano citado anteriormente nesta pesquisa e muito referido em estudos sobre evasão, formulou um modelo para o entendimento do fenômeno da evasão de alunos das escolas americanas. Para compreender a evasão escolar, afirma Tinto $(1994)^{10}$, é necessário averiguar a forma de relação existente entre a escola e o aluno, pois, quanto melhor for essa relação, menor será o abandono escolar. O problema da evasão, observa o autor, centra-se na falta de identificação do aluno com o grupo acadêmico, e os problemas que surgem estão ligados principalmente a questões sociais e à área do relacionamento humano. Na ótica de Tinto, portanto, a evasão ocorre quando o aluno não está integrado, de forma coerente, ao sistema acadêmico e social da escola, ou quando ele mesmo não percebe alguma vantagem na sua relação com a instituição educacional.

Os estudos de Schargel e Smink (2002), por estarem direcionados ao ensino médio, também contribuíram para este artigo. Eles analisam algumas situações que caracterizam a evasão escolar indicadas pelo National Center for Education Statistics (NCES), nos Estados Unidos (EUA), tendo como base o início do ano letivo daquele país, que se inicia no mês de outubro: a) estava [o aluno] matriculado em uma escola em algum período do ano letivo anterior, mas não se encontrava mais matriculado em $1^{\circ}$ de outubro do ano letivo em curso; b) não estava matriculado em $1^{\circ}$ de outubro do ano letivo anterior, embora devesse estar; c) não concluiu o segundo grau nem um programa educacional aprovado pelo estado ou pelo distrito; d) não atende qualquer das seguintes condições excludentes: transferência para escola pública de outro distrito, para uma escola particular ou para um programa educacional aprovado pelo estado ou pelo distrito, ausência temporária da escola por motivo de suspensão ou doença ou morte (SCHARGEL; SMINK, 2002, p. 17).

Outros fatores considerados relevantes pelos referidos autores no exame da evasão escolar no ensino médio são a complexidade e a variedade de situações que a permeiam.

10 TINTO, Vicent. Dropout from higher education: a theoretical synthesis of research. Chicago: Review of Educational Research, 1993 
Wander Augusto Silva

Além disso, ressaltam a existência de diversos outros tipos de fatores que incidem sobre o fenômeno da evasão, tais como o abandono eventual (o aluno abandona a escola e, depois de um período, a ela retorna), o abandono situacional (o aluno faz o curso, mas não o conclui e não recebe um certificado de segundo grau) e o abandono por contemporaneidade (refere-se ao conjunto de alunos que deixam o ensino médio ao longo de um período de formação). Alguns fatores, complementam Schargel e Smink (2002), incidem com maior frequência sobre a evasão escolar, tais como a necessidade de trabalho, a pobreza, a falta de formação básica de qualidade no ensino fundamental, a dificuldade de acesso à escola, o não gostar da escola, a violência, a gravidez, entre outros.

Nos EUA, o fenômeno da evasão escolar já é considerado um dos grandes problemas educacionais atuais, tendo sido criado o National Dropout Prevention Center (NDPC), em 1986, com a finalidade de estabelecer indicações para prevenir a evasão. Trata-se de uma organização que congrega representantes de empresas privadas e do setor educacional daquele país que trabalham com o intuito de reduzir o índice de abandono escolar, principalmente entre jovens em situação de risco de evasão. O NDPC realiza pesquisas de ação, coleta e analisa dados e informações com o objetivo de diminuir a evasão escolar. Também presta serviços de assistência e de qualificação a escolas que necessitem de auxílio pedagógico e administrativo quanto ao problema da desistência de alunos.

Entre as ações implementadas pelo NDPC, está a identificação de estratégias de prevenção do abandono escolar. Os governos estaduais norte-americanos adotaram medidas como o Home Instruction for Parents of Preschool Youngsters (HIPPY) ${ }^{11}$. Trata-se de um programa pré-escolar que oferece aos pais orientação para a instrução de seus filhos em casa. Segundo Schargel e Smink (2002), foram criados vários programas estaduais nos EUA, através do NDPC, que possibilitaram ao governo oferecer auxílio pedagógico a alunos em situação de risco de evasão. Grande parte dessas ações toma como modelo o princípio de Tinto sobre a relação do aluno com a escola em que estuda. São ações que têm como ponto de partida a relação do aluno com a escola, no intuito de identificar formas de melhorar as atividades de ensino. Com esse objetivo, procuram reforçar ações relacionadas à responsabilidade e ao envolvimento da família na vida escolar do aluno, além de ressaltarem a importância da adequada formação intelectual e moral das crianças nas séries iniciais de ensino.

Nos EUA, as principais razões para os estudantes e, especificamente, os alunos do ensino médio abandonarem a escola estão relacionadas, segundo Schargel e Smink (2002), à falta de sucesso na área acadêmica e às precárias habilidades sociais, como a incapacidade de convivência com colegas ou professores, a falta de sentido

11 Disponível em: <http://www.dropoutprevention.org/modelprograms/show_program.php?pid=196>. Acessado em: 22 abr. 2010. 
de participação e os problemas disciplinares. Para minimizar esses problemas que levam à evasão escolar, Schargel e Smink (2002) apresentam "Quinze estratégias mais eficazes de prevenção da dissidência escolar”, que serão comentadas a seguir.

A abordagem inicial dos autores refere-se à série de ações denominada intervenções precoces, com base em três tipos de intervenções. A primeira delas refere-se ao envolvimento da família, pois o auxílio, o envolvimento e a participação familiar são elementos considerados mais positivos para o sucesso escolar. Outro fator mencionado pelos autores é a atenção e a intervenção na educação infantil, que vai do nascimento aos três anos de idade. Os cuidados nessa fase, advertem Schargel e Smink (2002), proporcionam enriquecimento adicional à criança, ao lhe possibilitar nutrição adequada, vínculos emocionais e afetivos com seu grupo familiar, acesso ilimitado à assistência médica, ambiente físico seguro e previsível, baixo nível de estresse em casa e boa qualidade das creches, se for o caso. Por fim, e finalizando essa primeira abordagem, Schargel e Smink (2002) sugerem o Programa de leitura e redação para o auxílio das habilidades de leitura e de escrita, que podem gerar benefícios, pois ajudam todas as demais ações para se evitar a evasão escolar.

A segunda abordagem, denominada por Schargel e Smink (2002) de estratégias essenciais básicas, abrange quatro linhas de ação. As funções de orientador e do professor chamam a atenção para a relação individualizada e solidária entre orientando e orientador no desenvolvimento das noções de cidadania, linguagem e matemática. Outra, o aprendizado em serviço, afirmam os autores, relaciona experiências significativas do serviço comunitário ao aprendizado escolar. Para os autores, a atividade de trabalho do aluno para a comunidade torna-o mais responsável, proporciona-lhe crescimento pessoal e abertura para uma escolha profissional mais adequada no futuro. De acordo com esses autores, seria necessária também a adoção de escolas alternativas para possibilitar ao evadido condições de concluir seu curso de ensino médio em ambiente escolar diverso da escola regular. O enriquecimento extraescolar, através da oferta de cursos de reforço escolar, fora do horário normal de aula, é o item apresentado por Schargel e Smink (2002) para fechar as estratégias essenciais básicas.

O melhor aproveitamento da instrução é a terceira abordagem analisada por Schargel e Smink (2002). Eles a dividem em quatro fases, sendo a primeira o desenvolvimento profissional dos professores que trabalham com alunos em situação de risco de reprovação. Segundo esses autores, esses profissionais precisam de maior apoio institucional para desenvolver melhores ações pedagógicas aos alunos em tal situação. Também a receptividade a diversos tipos de aprendizado e de inteligências múltiplas é enfocada por Schargel e Smink (2002). Significa, na visão deles, que os educadores devem mostrar aos alunos a possibilidade de diversas maneiras de aprender. A utilização das tecnologias instrucionais, outro ponto abordado pelos referidos autores, está diretamente ligada ao item anterior, pois envolve a utilização da tecnologia da informação para se multiplicar a forma de ensinar. A possibilidade de oferecer 
um aprendizado individualizado ao aluno em risco de evasão é considerada muito importante para Schargel e Smink (2002). Afirmam esses autores que os professores devem ter um tempo para trabalhar, individualmente, com cada aluno, as maiores necessidades deles.

A última seção abordada por Schargel e Smink (2002) é denominada o melhor aproveitamento da comunidade mais ampla. Eles partem do princípio de que o aluno que ingressa no ensino médio sempre está inserido em determinada comunidade, com a qual mantém vínculos que devem ser observados durante o curso e, principalmente, após sua conclusão. No item renovação sistêmica, é enfatizada a importância de um processo contínuo de avaliação das metas e dos objetivos das escolas relacionados às políticas, às práticas e à estrutura organizacional. Também a cooperação comunitária é necessária, com grupos de pessoas da comunidade prestando apoio à escola. Outro fator apontado dentro dessa seção refere-se à educação profissional e a habilitação para a força de trabalho. Educação profissional implica um trabalho de orientação e de preparação do aluno do ensino médio, não apenas para o mercado de trabalho, mas também para a formação pessoal e para o esclarecimento sobre o mundo do trabalho. Finalizando a apresentação das “Quinze estratégias mais eficazes de prevenção da dissidência escolar”, os autores analisam a resolução de conflito e a prevenção da violência. Para eles, a escola deve estabelecer um plano de ação para o fim da violência. Assim, eles consideram importante a elaboração de um plano de intervenção tanto contra a violência potencial quanto da administração da crise, que gera a violência na escola. Sugerem, então, experiências diárias que despertem atitudes sociais positivas e habilidades interpessoais em todos os alunos.

\section{Algumas estatísticas sobre a evasão escolar no Brasil}

Além dos autores e dados já discutidos sobre o fenômeno da evasão no ensino médio no Brasil neste artigo, serão apresentados alguns dados estatísticos referentes a esse tema que, apesar de reduzidos, mostram indicadores preocupantes. O primeiro deles apresenta a taxa percentual de abandono escolar no Brasil, no ensino médio, por Unidade da Federação, entre os anos de 2007 e 2010, feito pelo Instituto Brasileiro de Geografia e Estatísticas (IBGE). Esse trabalho revela a existência de alto índice de abandono escolar registrado no ensino médio como um todo, formação geral e profissional (tabela 1). Assim, nos anos de 2007 a 2010, ocorreram índices expressivos de abandono escolar (24,2\%) e uma média geral relativa (14,0\%). Entretanto, observase um aspecto positivo: a queda da taxa percentual de evasão, entre os anos de 2007 e 2010, em todos os estados do Brasil, alguns com maior aceleração do que outros. O estado de São Paulo foi a Unidade da Federação que apresentou o menor índice de evasão, com uma queda expressiva de abandono no ano de 2009 (3,9\%). Contudo, a tendência de queda não se manteve e, no ano de 2010, ela aumentou para 4,5\%. Já o 
Rio Grande do Norte é o estado com maior porcentagem de evadidos no ensino médio, no Brasil, no ano de 2007 (24,7\%), sendo reduzida em 2010 (17,3\%).

Tabela 1 - Taxa percentual de abandono escolar no ensino médio (Brasil/Estados), 2007-2010

\begin{tabular}{|c|c|c|c|c|c|}
\hline Colocação & UF & 2007 & 2008 & 2009 & 2010 \\
\hline $1^{\circ}$ & Pará & 20,0 & 22,0 & 20,7 & 19,2 \\
\hline $2^{\circ}$ & Alagoas & 19,9 & 17,0 & 19,2 & 17,8 \\
\hline $3^{\circ}$ & Paraíba & 18,9 & 18,8 & 17,8 & 17,4 \\
\hline $4^{\circ}$ & R. G. do Norte & 24,2 & 22,7 & 20,9 & 17,3 \\
\hline $5^{\circ}$ & Piauí & 19,7 & 22,2 & 20,2 & 16,7 \\
\hline $6^{\circ}$ & Bahia & 19,9 & 19,8 & 18,5 & 15,7 \\
\hline $7^{\circ}$ & Sergipe & 18,3 & 18,4 & 16,2 & 15,5 \\
\hline $8^{\circ}$ & Amapá & 19,6 & 18,4 & 17,5 & 15,3 \\
\hline $9^{\circ}$ & Maranhão & 17,5 & 16,2 & 13,8 & 14,7 \\
\hline $10^{\circ}$ & Rio de Janeiro & 14,0 & 14,8 & 13,8 & 12,8 \\
\hline $11^{\circ}$ & Acre & 14,9 & 14,3 & 12,8 & 12,5 \\
\hline $12^{\circ}$ & Goiás & 15,9 & 15,1 & 12,0 & 11,7 \\
\hline $13^{\circ}$ & Rondônia & 13,2 & 12,7 & 11,6 & 11,5 \\
\hline $14^{\circ}$ & Mato Grosso & 17,9 & 19,4 & 15,8 & 11,2 \\
\hline $15^{\circ}$ & Pernambuco & 22,0 & 18,0 & 14,0 & 11,1 \\
\hline $16^{\circ}$ & R. G. do Sul & 13,0 & 12,4 & 11,7 & 11,0 \\
\hline $17^{\circ}$ & M. G. do Sul & 12,7 & 11,9 & 11,8 & 11,0 \\
\hline $18^{\circ}$ & Ceará & 14,7 & 13,8 & 13,0 & 10,6 \\
\hline $19^{\circ}$ & Amazonas & 11,2 & 14,1 & 13,4 & 10,2 \\
\hline $20^{\circ}$ & Minas Gerais & 12,0 & 11,0 & 9,3 & 8,8 \\
\hline $21^{\circ}$ & Tocantins & 11,7 & 11,3 & 8,7 & 8,0 \\
\hline $22^{\circ}$ & Santa Catarina & 7,1 & 7,3 & 6,8 & 7,1 \\
\hline $23^{\circ}$ & Espírito Santo & 12,5 & 11,5 & 10,7 & 7 \\
\hline $24^{\circ}$ & Roraima & 8,9 & 8,7 & 7,8 & 6,9 \\
\hline $25^{\circ}$ & Paraná & 9,0 & 10,3 & 8,3 & 6,7 \\
\hline $26^{\circ}$ & São Paulo & 5,2 & 4,3 & 3,9 & 4,5 \\
\hline
\end{tabular}

Fonte: IBGE, 2011.

Outra perspectiva de análise seria a verificação sobre o total de alunos matriculados nos anos finais do ensino fundamental, em comparação com o total de alunos matriculados no ensino médio no Brasil. No ano de 2010, por exemplo, conforme 
dados do INEP ${ }^{12}$, havia 14.250.000 alunos matriculados nos anos finais do ensino fundamental; nesse mesmo ano, existiam somente 8.357.675 alunos cursando o ensino médio. É desproporcional o número de alunos que finalizavam o ensino fundamental, em 2010, em relação ao número de alunos que cursavam o ensino médio naquele ano. Atualizando esses dados para o ano de 2015, também conforme o INEP, tinha-se um número de 12.368.000 alunos que estavam matriculados nas séries finais do ensino fundamental, enquanto existiam apenas 8.076.000 estudantes matriculados no ensino médio em 2015. Apesar de essa relação ter melhorado um pouco no ano de 2015, apenas $21 \%$ do total dos alunos do ensino básico eram do ensino médio. Supõe-se, pois, que muitos jovens em idade escolar para cursar o ensino médio nem iniciaram essa etapa final da formação básica. Não se pode deixar de ressaltar, observando essa análise comparativa entre os anos de 2010 e 2015, a diminuição de alunos matriculados, tanto no ensino fundamental quanto no ensino médio, nesse período, no Brasil.

A análise sobre os gastos públicos em relação ao ensino médio é um elemento importante para uma ideia mais apurada sobre a questão da evasão escolar. A tabela 2 apresenta os dados do Fundo Nacional do Desenvolvimento da Educação (FNDE) ${ }^{13}$, que fornece o valor gasto por cada estado do Brasil no ensino médio, sobre o ano de 2010, indicam uma variação de mais de $85 \%$ entre os estados que mais investem e os que menos investem. Assim, existiam estados que mais aplicavam recursos, como Roraima, com o valor de R \$ 3.199,84, São Paulo, R \$ 2.782,49, e o Espírito Santo, R \$ 2.549,46 por aluno do ensino médio em 2010; enquanto Paraíba, Maranhão, Pernambuco e Ceará determinavam apenas R \$1.669,17; e o Pará, somente R \$1.769,96, nesse mesmo ano, para seus alunos do ensino médio; ou seja, esses estados eram os que menos aplicavam. Também podemos inferir que existe uma relação quase direta entre o investimento por aluno e a taxa de evasão escolar. Utilizando os dados da tabela 1, sobre a evasão no ensino médio por estado brasileiro, em sobreposição com os dados da tabela 2, sobre o volume de gasto por aluno nessa modalidade educacional, constatamos que, quanto maior o investimento, menor é a evasão. São Paulo, Roraima e Espírito Santo, junto com o Paraná, são os estados que têm os menores índices de abandono no ensino médio e que mais investiam nessa modalidade no Brasil. Em proporção inversa, os estados com maior taxa de evasão eram os que menos investiam no ensino médio, como Pará, Paraíba, Maranhão e Rio Grande do Norte.

12 Conforme dados obtidos através do Instituto Nacional de Estudos e Pesquisa Anísio Teixera, INEP, Sinopses Estatísticas, 2010.

13 Fundo Nacional de Desenvolvimento da Educação no Brasil (FNDE). Dados disponíveis em: <http://www.fnde.gov. br/financiamento/fundeb/fundeb-consultas>. Acesso em: 20 dez. 2016. 
Evasão Escolar no Ensino Médio no Brasil

Tabela 2 - Gasto menor por aluno, por estado, no Brasil, no ano de 2010

\begin{tabular}{|c|c|c|}
\hline Colocação & Estado & Gasto \\
\hline $1^{\circ}$ & Paraíba & $1.699,17$ \\
\hline $2^{\circ}$ & Piauí & $1.699,17$ \\
\hline $3^{\circ}$ & Maranhão & $1.699,17$ \\
\hline $4^{\circ}$ & Pernambuco & $1.699,17$ \\
\hline $5^{\circ}$ & Ceará & $1.699,17$ \\
\hline $6^{\circ}$ & Pará & $1.769,96$ \\
\hline $7^{\circ}$ & R. G. do Norte & $1.762,98$ \\
\hline $8^{\circ}$ & Paraná & $1.885,29$ \\
\hline $9^{\circ}$ & Sergipe & $1.947,39$ \\
\hline $10^{\circ}$ & Minas Gerais & $1.952,81$ \\
\hline $11^{\circ}$ & Goiás & $2.035,56$ \\
\hline $12^{\circ}$ & Rondônia & $2.046,67$ \\
\hline $13^{\circ}$ & Rio de Janeiro & $2.062,56$ \\
\hline $14^{\circ}$ & Mato Grosso & $2.144,83$ \\
\hline $15^{\circ}$ & Santa Catarina & $2.175,08$ \\
\hline $16^{\circ}$ & Tocantins & $2.303,67$ \\
\hline $17^{\circ}$ & R. G. do Sul & $2.406,27$ \\
\hline $18^{\circ}$ & M. Grosso do Sul & $2.476,66$ \\
\hline $19^{\circ}$ & Espírito Santo & $2.549,46$ \\
\hline $20^{\circ}$ & São Paulo & $2.782,49$ \\
\hline $21^{\circ}$ & Roraima & $3.199,84$ \\
\hline $22^{\circ}$ & Alagoas & $\mathrm{s} / \mathrm{d}$ \\
\hline $23^{\circ}$ & Bahia & s/d \\
\hline $24^{\circ}$ & Amapá & $\mathrm{s} / \mathrm{d}$ \\
\hline $25^{\circ}$ & Acre & $\mathrm{s} / \mathrm{d}$ \\
\hline $26^{\circ}$ & Amazonas & $\mathrm{s} / \mathrm{d}$ \\
\hline
\end{tabular}

Fonte: FNDE, 2016.

Outro estudo feito no Brasil sobre a evasão escolar no ensino médio foi realizado pela Fundação Getúlio Vargas (FGV), em 2009. Nessa pesquisa, conforme Neri (2009) ${ }^{14}$, é indicada a tendência acentuada de abandono da escola média nos anos de 2004 e 2006. Seus resultados mostram que, em 2006, 17,8\% dos jovens entre 15

14 NERI, Marcelo Côrtes (Coord.). O tempo de permanência na escola e as motivações dos sem-escola. Rio de Janeiro: FGV/IBRE, CPS, 2009. 
e 17 anos abandonaram a escola já no primeiro ano de estudos. Dentre os principais motivos encontrados para tal evasão escolar, destacam-se: a) trabalho (27,09\%), b) falta de acesso (10,89\%) e c) desinteresse (40,29\%). Portanto, de acordo com os dados dessa investigação, apesar de podermos fazer considerações sobre a imprecisão das perguntas apresentadas aos respondentes para indicar a causa do abandono no ensino médio, a desorientação e o desinteresse destacam-se como os principais motivos para a evasão, seguidos pela busca e pela necessidade de emprego, não conciliável com tempo para o estudo.

Contudo, o Governo Federal da época parecia se preocupar com o problema da evasão escolar. O tema ainda tem sido objeto de políticas públicas voltadas para a educação no Brasil. Dentre elas, encontram-se pelo menos dois programas de avaliação de ensino, como o Índice de Desenvolvimento da Educação Básica (IDEB) e o Exame Nacional do Ensino Médio (ENEM), cujo principal objetivo não é apenas verificar a qualidade do ensino (aquisição de conhecimentos), mas também fazer diagnósticos para evitar o desinteresse, a evasão e o fracasso escolar.

O IDEB foi criado pelo MEC em 2007, através do INEP. Seu propósito é reunir, num só indicador, dois conceitos igualmente importantes para a qualidade da educação: fluxo escolar e médias de desempenho nas avaliações. Esse índice agrega ao enfoque pedagógico os resultados das avaliações em larga escala realizadas pelo INEP, possibilitando a obtenção de resultados sintéticos e resumidos, facilmente assimiláveis, tornando-se possível traçar metas de qualidade educacional para os sistemas. O indicador é calculado tomando-se os dados da aprovação escolar, obtidos pelo Censo Escolar, e as médias de desempenho nas avaliações do INEP, como as do Sistema Nacional de Avaliação da Educação Básica (SAEB), para as Unidades da Federação e para o país, e as da Prova Brasil ${ }^{15}$, para os municípios.

\section{Considerações finais}

Podemos destacar, ao final deste artigo, alguns aspectos constatados em relação ao ensino médio e à evasão escolar. Primeiramente, que grande parte dos estudos sobre o abandono escolar e sobre as estratégias para diminuí-la está relacionada ao ensino superior; poucos são os estudos sobre o ensino médio, e, no Brasil, existem menos pesquisas ainda.

Na curta análise feita sobre estudos relacionados ao abandono escolar em alguns países do mundo, verificamos que, nos EUA, existe bom volume de textos sobre

15 SAEB e Prova Brasil são avaliações para diagnóstico em larga escala, desenvolvidas pelo INEP/MEC, que objetivam avaliar a qualidade do ensino oferecido pelo sistema educacional brasileiro a partir de testes padronizados e de questionários socioeconômicos. Nos testes, os estudantes respondem a itens (questões) de Língua Portuguesa, com foco em leitura, e de Matemática, com ênfase na resolução de problemas. No questionário socioeconômico, os estudantes fornecem informações sobre fatores de contexto que podem estar associados ao desempenho. 
o fenômeno, com vários autores indicando, através de pesquisas, possibilidades e estratégias para a permanência de alunos em escolas. Os estudos mostram que, nesse país, existe a preocupação clara com a evasão escolar; algumas instituições públicas criaram mecanismos e ações nesse sentido, e focam sua atuação de intervenção sobre o aluno propenso à evasão e a sua relação com a própria escola, com a família e com o entorno social.

No Chile, a visão apresentada é de um país bastante dividido em sua educação, com uma oligarquia econômica tendo privilégios, com uma formação propedêutica e com mínimos índices de evasão, enquanto as classes mais pobres da população recebem uma formação de menor qualidade e destinada basicamente ao trabalho imediato, sendo alarmante o abandono escolar no país por essa parcela da população. Na Argentina, desde 2006, já existe a obrigatoriedade de o Estado manter a gratuidade e a qualidade para o ensino médio. Entretanto, os dados da UNESCO indicam que, na América Latina, quase como um todo, é elevado o índice de evasão em todos os níveis do ensino, concorrendo, para isso, o baixo investimento dos governos na educação para as classes mais pobres, assim como uma herança colonial que se espelha na exclusão de afrodescendentes, da população indígena, da população rural e também na marginalização da condição feminina.

Além desses fatores externos, visualizados pela falta de políticas públicas para a diminuição da evasão escolar, poderíamos indicar, conforme Silva (2013), os principais motivos internos e pessoais para o abandono escolar como a pobreza de famílias e estudantes, o nível cultural da família, a necessidade da busca por trabalho e a consequente dificuldade de conciliar trabalho e estudo, assim como o desconhecimento do aluno sobre o curso que faz, levando à não adequação e à insatisfação, a falta de formação de professores para lidar com os alunos em situação de abandono e, por fim, a falta de base educacional e de conteúdo do aluno, que gera repetência e desinteresse.

Outra constatação que é alarmante no ensino brasileiro concerne ao número de alunos que estão nos anos finais do ensino fundamental, em relação ao total de estudantes que estão no ensino médio, ou seja, cerca de $40 \%$ de jovens em faixa etária para estudar no ensino médio não ingressam ou não estudam nessa modalidade, encerrando seus estudos no ensino fundamental. Os que tentam dar prosseguimento com o ensino médio enfrentam variadas dificuldades, o que eleva as taxas de evasão. Existem indicadores que demonstram que os estados brasileiros que mais investem no ensino médio obtêm uma porcentagem menor de evasão escolar, e que, em sentido contrário, os estados que menos investem têm uma porcentagem maior de evasão.

Além disso, não existem políticas públicas diretas para tratar do abandono escolar, por parte do setor público brasileiro. Portanto, o fenômeno da evasão escolar no ensino médio no Brasil necessita de um número mais elevado de pesquisas sobre a evasão no ensino médio que indiquem caminhos para a ação de políticas públicas que diminuam esse sério problema educacional e social. 
Wander Augusto Silva

\section{Referências}

ABRAMO, H.W. Considerações sobre a tematização social da juventude no Brasil. In: BRASIL. Juventude e contemporaneidade. Brasília, DF: UNESCO; MEC; ANPEd, 2007. (Coleção Educação para Todos; 16).

BIAZUS, Cleber Augusto. Sistema de fatores que influenciam o aluno a evadir-se dos cursos de graduação na UFSM e na UFSC: um estudo no curso de Ciências Contábeis. 190 f. 2003. Tese (Doutorado em Engenharia da Produção) - Universidade Federal de Santa Catarina, Florianópolies, 2004.

BRASIL. Comissão Especial de Estudos sobre a Evasão nas Universidades Públicas Brasileiras. Brasília, DF: Ministério da Educação; Secretaria de Educação Superior, 1996. Disponível em: <http://www.dominiopublico.gov.br/download/texto/ me001613.pdf>. Acesso em: 06 abr. 2012.

Séries Estatísticas. Rio de Janeiro: IBGE, 2011. Disponível em: <http:// seriesestatisticas.ibge.gov.br>. Acesso em: 20 jan. 2012.

Sinopse dos resultados do Censo 2010. Rio de Janeiro: IBGE, 2011. Disponível em: <http://www.censo2010.ibge.gov.br/sinopse/webservice/default. php?cod1=0\&cod2=\&cod3=0\&frm=piramide $>$. Acesso em: 12 mai. 2012.

DORE, R.; LÜSCHER, A. Educação profissional e evasão escolar. In: ENCONTRO INTERNACIONAL DE PESQUISADORES DE POLÍTICAS EDUCATIVAS ASSOCIAÇÃO DE UNIVERSIDADES GRUPO MONTEVIDÉU, 3., 2008, Porto Alegre. Anais... Porto Alegre: UFRGS/FACED, 2008. p. 197-203.

FREITAS, Kátia Siqueira de. Alguns estudos sobre evasão e persistência de estudantes. EccoS, São Paulo, v. 2, n. 1, p. 247-264, jun. 2009.

MARTÍNEZ, Eusebio Nájera. Educación y trabajo juvenil: los desafíos de la educación media técnico profesional en Chile. In: DORE, Rosemary; ARAÚJO, Adilson César de; MENDES, Josué de Sousa (Org.). Evasão na educação: estudos, políticas e propostas de enfrentamento. Brasília, DF: IFB/CEPROTEC/RIMEPES, 2014.

MARTINS, Cleidis Beatriz Nogueira. Evasão de alunos nos cursos de graduação em uma instituição de ensino superior. Dissertação (Mestrado em Educação) Faculdades Integradas de Pedro Leopoldo, Pedro Leopoldo, 2007.

PASSADES, Bianca Denise M. Expansão e evasão no ensino médio e técnico no Brasil e Argentina. In: In: DORE, Rosemary; ARAÚJO, Adilson César de; MENDES, Josué de Sousa (Org.). Evasão na educação: estudos, políticas e propostas de enfrentamento. Brasília, DF: IFB/CEPROTEC/RIMEPES, 2014.

TINTO, Vicent. Dropout from higher education: a theoretical synthesis of research. Chicago: Review of Educational Research, 1993. 
SCHARGEL, Franklin P.; SMINK, Jay. Estratégias para auxiliar o problema de evasão escolar. Tradução de Luiz Frazão Filho. Rio de Janeiro: Dunya, 2002.

SILVA, Wander Augusto. Fatores de permanência e evasão no Programa de Educação Profissional de Minas Gerais (PEP/MG): 2007 a 2010. 216 f. 2013. Tese (Doutorado em Educação) - Universidade Federal de Minas Gerais, Belo Horizonte, 2013.

SPOSITO, Marilia P. Transversalidades no estudo sobre jovens no Brasil. Educação e Pesquisa, São Paulo, v. 36, n. especial, p. 95-106, 2010.

UNESCO; UNICEF. Todas as crianças na escola em 2015 - iniciativa global pelas crianças fora da escola. 2012. Disponível em:

$<$ http://www.uis.unesco.org/Education/Documents/OOSCI\%20Reports/brazil-ooscireport-2012-pr.pdf>. Acesso em: 26 dez. 2016.

UNICEF. El aprendizaje bajo la lupa: nuevas perspectivas para América Latina y el Caribe (A aprendizagem sob a lupa: novas perspectivas para a América Latina e o Caribe). 2015. Disponível em:

$<$ https://www.unicef.org/lac/UNICEF_Aprendizaje_bajo_la_lupa_nov2015(1).pdf>. Acesso em: 27 dez. 2016. 